\title{
New Proteins Found Interacting with Brain Metallothionein-3 Are Linked to Secretion
}

\author{
Issam El Ghazi, Bruce L. Martin, and Ian M. Armitage \\ Biochemistry, Molecular Biology and Biophysics, University of Minnesota, 6-155 Jackson Hall, 321 Church Street, SE, \\ Minneapolis, MN 55455, USA \\ Correspondence should be addressed to Ian M. Armitage, armitage@msi.umn.edu
}

Received 19 August 2010; Revised 19 October 2010; Accepted 5 November 2010

Academic Editor: Peter Faller

Copyright ( $\odot 2011$ Issam El Ghazi et al. This is an open access article distributed under the Creative Commons Attribution License, which permits unrestricted use, distribution, and reproduction in any medium, provided the original work is properly cited.

Metallothionein 3 (MT-3), also known as growth inhibitory factor (GIF), exhibits a neuroinhibitory activity. Our lab and others have previously shown that this biological activity involves interacting protein partners in the brain. However, nothing specific is yet known about which of these interactions is responsible for the GIF activity. In this paper, we are reporting upon new proteins found interacting with MT-3 as determined through immunoaffinity chromatography and mass spectrometry. These new partner proteins-Exo84p, 14-3-3 Zeta, $\alpha$ and $\beta$ Enolase, Aldolase C, Malate dehydrogenase, ATP synthase, and Pyruvate kinase-along with those previously identified have now been classified into three functional groups: transport and signaling, chaperoning and scaffolding, and glycolytic metabolism. When viewed together, these interactions support a proposed model for the regulation of the GIF activity of MT-3.

\section{Introduction}

In a comparative study, Uchida et al. found that brain extract from Alzheimer's disease (AD) patient had an enhanced neurotrophic effect when compared to normal brain extract [1]. This was subsequently attributed to the reduction of a protein originally called, growth inhibitory factor (GIF). The latter was first thought to be involved in the formation of the senile plaques, which leads to the enhanced sprouting and the exhaustion of the neurons and, therefore, increases the susceptibility of the neurons to exocitotoxic substances [2]. However, in a followup study, a correlation was found between the reduction of the GIF activity and the presence of neurofibrillary tangles and not with the senile plaques [3]. Further isolation, purification, and sequencing of the GIF revealed that it belonged to the metallothionein (MT) protein family, the third isoform isolated and purified in this family, thus the name metallothionein-3 (MT-3) [3].

MTs are a class of small $(6-7 \mathrm{kDa})$ cysteine-rich $(30 \%)$ proteins binding both essential $\left(\mathrm{Cu}^{+}\right.$and $\left.\mathrm{Zn}^{2+}\right)$ and nonessential $\left(\mathrm{Cd}^{2+}, \mathrm{Ag}^{+}\right.$and $\left.\mathrm{Hg}^{2+}\right)$ metal ions [4]. While metal binding is very tight, there is a facile metal exchange between
MTs and other metalloproteins [5]. In mammalian species, four isoforms are currently known, which are designated as MT-1, 2, 3, and 4 [6]. MT-1 and 2 are expressed in almost every organ, particularly high in the kidney and liver and both exhibit similar properties as far as metal-binding characteristics are concerned. MT-3 is expressed mainly in the brain, though some studies have reported finding MT-3 in the kidney and some cancer cells [7]. MT-4 is expressed in certain stratified tissues [8].

Since the discovery of MT-1 and MT-2, there have been numerous publications describing the biochemical characteristics and possible function of these isoforms [9]. Although the essential physiological functions remain elusive, MT's have been shown to be involved in these vital processes: (1) the modulation of free oxygen radicals and nitric oxide [10], (2) apoptosis [11], and (3) homeostasis of heavy metals [4]. All three physiological processes play a key role in several diseases [9].

The binding of metal ions occurs, specifically through cysteine thiolate bonds, in two separate domains. The $\mathrm{N}$ terminal domain, called $\beta$-domain, binds 3 divalent metals in a $\mathrm{Me}_{3} \mathrm{~S}_{9}$ tetrahedral coordination. The C-terminal domain, 
called $\alpha$-domain, binds 4 divalent metals in a $\mathrm{Me}_{4} \mathrm{~S}_{11}$ tetrahedral coordination $[12,13]$. While MT-1 and MT-2 have been shown to be inducible at the transcriptional level by the very heavy metals that they bind, such as $\mathrm{Cd}, \mathrm{Cu}$, and Zn [14], MT-3 is not induced by metal ions. Indeed, MT-3 and MT-1 respond differentially to zinc deprivation of cells in culture with only MT-1 being downregulated in these cells [15]. Thus, it is reasonable to conclude that MT-3 is not involved in metal ion homeostasis, as both the MT-1 and MT-2 isoforms appears to be $[4,14]$.

Studies have shown that the MT- $3 \beta$-domain was sufficient to exhibit the GIF activity [16-18]. However, MT-3 by itself does not exhibit GIF activity when added to neuronal cell cultures. This activity is only expressed when combined with brain extracts [17]. From this, one can conclude that the inhibitory activity is invoked by specific interaction(s) between MT-3 and other component(s) in the brain extract. Indeed, we and others have previously described some other components in the brain interacting with MT-3 [19-23].

Immunoaffinity chromatography is a highly sensitive and selective method for the isolation of target proteins and for the identification of protein-protein interactions [20]. The results from these experiments presented in this current paper represent a significant extension with 7 new proteins positively identified interacting with MT3, along with the 5 proteins identified in the preliminary mass spectra analysis of the bands in the tryptic digested gel [21]. Selected protein binding partners identified in Lahti et al. [21] were validated using antisera available for the associated proteins. A recent paper appeared by Chung et al. [24], which showed the release of MT-1 and 2 from astrocytes and uptake in neurons in response to brain injury. The mechanism of the secretion of these two MT isoforms, however, is quite distinct from the mechanism proposed here for MT-3. In this paper, we present a detailed description of new proteins found interacting with MT-3, which leads us to propose a new model for the secretion of MT-3 from the astrocytes and uptake in neurons, thus providing the first mechanistic description of its neuroinhibitory activity.

\section{Materials and Methods}

2.1. Protein Extraction. Whole mouse ( $8-10$ weeks) brains (Swiss Webster, Pel-Freez) were used for total protein extraction. The brains were homogenized at a ratio of $2: 1(\mathrm{v} / \mathrm{w})$ in $10 \mathrm{mM}$ MOPS, $10 \mathrm{mM} \mathrm{NaCl}, \mathrm{pH} 7.0$ containing $1 \mathrm{mM}$ PMSF and EDTA-free protease inhibitor cocktail (Roche). The homogenate was then centrifuged at $30000 \mathrm{~g}, 4^{\circ} \mathrm{C}$ for $30 \mathrm{~min}$. The supernatant thus obtained was used for the MT3 protein complex purification.

2.2. Affinity Chromatography. Affi-Gel $\mathrm{Hz}$ (Biorad) was used to immobilize the MT-3 antibody previously purified [25]. The supernatant was applied to the column and incubated overnight. The nonbound fraction was then thoroughly washed with the homogenization buffer. The column was then rinsed with $10 \mathrm{mM}$ MOPS, $150 \mathrm{mM} \mathrm{NaCl} \mathrm{pH} 7.0$ containing $1 \mathrm{mM}$ PMSF and the protease inhibitor cocktail

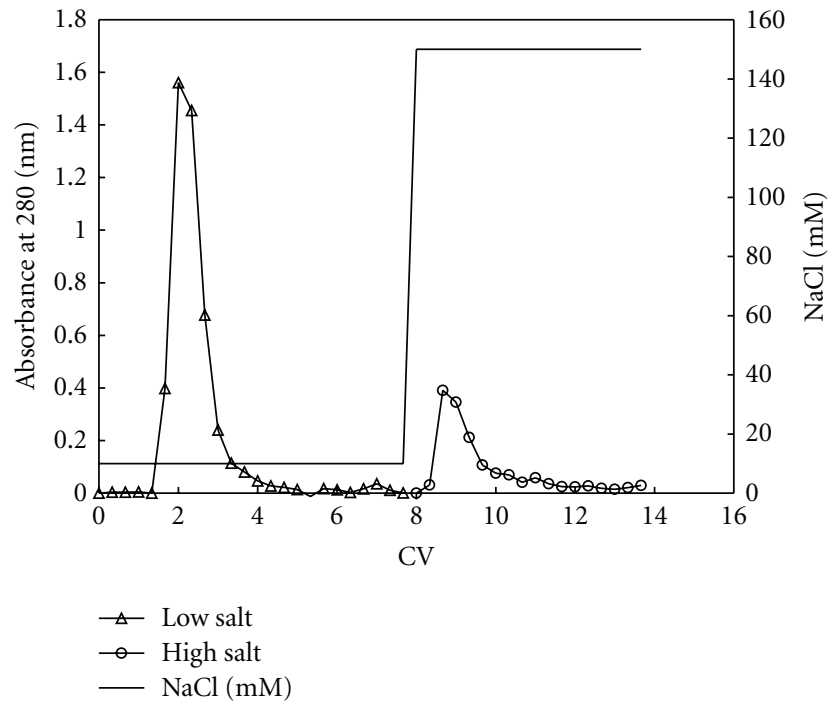

FIgURE 1: Washing steps for the immunoaffinity column. After loading the column was washed with different salt concentration until no protein was eluted (absorbance at $280 \mathrm{~nm}$ ).

until no protein was eluted from the column (see Figure 1). The MT-3 protein complex was then chaotropically eluted using $10 \mathrm{mM}$ MOPS, $3 \mathrm{M}$ NaSCN, pH 7.0. The MT-3 protein complex was then concentrated using a spin-filter with MWCO of $3 \mathrm{kDa}$ and the buffer exchanged to the homogenization buffer.

2.3. SDS-PAGE and In-Gel Trypsin Digestion. The MT3 protein complex fraction was then SDS-paged using NuPAGE Novex 4-12\% Bis-Tris gel and run for $30 \mathrm{~min}$ at $200 \mathrm{~V}$ using MES-SDS buffer (Invitrogen). The gel was then silver-stained using an enhanced silver stain kit (Biorad).

Protein bands were excised using the Investigator Proprep from Genomics Solutions. The digestion of the band was done according to a modified procedure [26]. Briefly, bands were excised and destained using $30 \mathrm{mM}$ potassium ferricyanide and $100 \mathrm{mM}$ sodium thiosulphate, washed with Milli-Q and then with $100 \%$ acetonitrile, followed by SpeedVac for $30 \mathrm{~min}$. Trypsin (sequence-grade modified porcine, Promega) was then added to a final concentration of $12.5 \mathrm{ng} / \mu \mathrm{L}$ in ice-cold $50 \mathrm{mM}$ ammonium bicarbonate containing $5 \mathrm{mM} \mathrm{CaCl}_{2}$. The mixture was incubated on ice for 1 hour and then at $37^{\circ} \mathrm{C}$ overnight. The supernatant was removed and the gel slices washed once with $20 \mathrm{mM}$ ammonium bicarbonate for $20 \mathrm{~min}$ and then pooled together. The gel slices were washed three times with $30 \mu \mathrm{L}$ of $50 \%$ acetonitrile $/ 5 \%$ formic acid for $20 \mathrm{~min}$ each, and then pooled with the previous supernatant.

The collected supernatant was then SpeedVac to near dryness and subjected to cysteine reduction and alkylation. This was done by rehydration in $10 \mathrm{mM}$ DTT/ $100 \mathrm{mM}$ $\mathrm{NH}_{4} \mathrm{HCO}_{3}$ at $56^{\circ} \mathrm{C}$ for $45 \mathrm{~min}$. After cooling the sample to room temperature, alkylation was conducted using freshly made $55 \mathrm{mM}$ iodoacetamide, $100 \mathrm{mM} \mathrm{NH}_{4} \mathrm{HCO}_{3}$, for $30 \mathrm{~min}$ at room temperature in dark. 


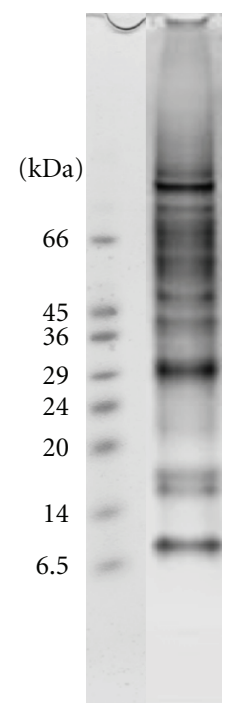

Figure 2: 4-12\% SDS-PAGE of the fractions collected from the immunoaffinity chromatography of the normal mouse brain homogenate. Lane 1: Markers, Lane 2: fractions collected with $3 \mathrm{M}$ NaSCN, 10 mM MOPS, pH 7.6.

2.4. Mass Spectrometry Analysis. MALDI-TOF data were collected on a Biflex III instrument (Bruker Daltonics). Full mass scans were collected, in the positive ion mode between $\mathrm{m} / \mathrm{z} 500$ and 3500, for the peptide mixtures of each sample placed on an anchor chip target. Each peak list of measured peptide masses was then used to search the National Center of Biotechnology Information (NCBI) sequence database for protein identification using Mascot (http://www.matrixscience.com/). Searches were performed allowing modifications that included methionine oxidation and carbamidomethyl addition, as well as up to 1 missed cleavage site and up to $250 \mathrm{ppm}$ mass error. Only hits with $P<.05$ were considered positive hits, where $P$ is the probability that the observed match is a random event.

MS-MS experiments were preformed on a linear ion trap (LTQ, Thermo Electron Corp., San Jose, CA) using nanoscale microcapillary reversed-phase liquid chromatography electrospray ionization tandem mass spectrometry (LC-MS/MS). Peptide mixtures were auto sampled on a Paradigm MS4 system (Michrom Bioresources, Inc., Auburn, CA). Samples were desalted and concentrated on a Paradigm Platinum Peptide Nanotrap precolumn $(0.15 \times 50 \mathrm{~mm}$, Michrom Bioresources, Inc.) and subsequently on a fused silica microcapillary column ( $75 \mu \mathrm{m}$ i. d.) packed in-house with Magic C18AQ reversed-phase material on a flow splitter (Michrom Bioresources, Inc.) at a flow rate of approximately $250 \mathrm{NL} / \mathrm{min}$. The samples were subjected to a $60 \mathrm{~min}(10-40 \% \mathrm{ACN})$ gradient and directly eluted into the microcapillary column set to $2.0 \mathrm{kV}$. The LTQ was operated in the positive-ion mode using data-dependent acquisition methods initiated by a survey MS scan, which was followed by MS/MS (collision energy of 29\%) on the 4 most abundant ions detected in the survey scan. $M / Z$ values selected in the survey scan for MS/MS were excluded for subsequence
MS/MS for $30 \mathrm{sec}$. The signal intensity threshold for an ion to be selected for MS/MS was set to a lower limit of 1000 . Mass spectra were analyzed using BioWorks SeQuest Analysis Software package (ABI, Inc., Foster City, CA). Proteins that contained peptides with Sequest cross-correlation scores greater than 2 and contained 2 or more peptides were further examined manually.

\section{Results}

The analysis of the MT-3 protein complex(es) with SDSPAGE revealed the presence of about 16 bands (Figure 2). Twelve proteins have been confidently identified thus far using MALDI-TOF and MS/MS. All the proteins reported previously to interact with MT-3 $[19,21]$ were reproducibly detected. New proteins found in the current study include: Exocyst complex component 8 (Exo84p), $\alpha$ and $\gamma$-enolase, 14-3-3 zeta, Malate dehydrogenase, Fructose-biphosphate aldolase 3 , and ATP synthase (Table 1). The low MW protein region $(<24 \mathrm{kDa})$ did not yield sufficiently significant scores for protein identification with high confidence. Rab3A [22, 23] was not identified although a faint band was seen in the gel with a MW of about $20 \mathrm{kDa}$. No significant protein $(P<.05)$ was found for this band when searching the database, however the hit returned was for a GTP-binding protein.

To confirm the ID of the newly identified proteins, we conducted ESI-MS/MS on the trypsin digest of the bands. Results were analyzed using Sequest software. The sequence of the peptide was considered a positive hit if the crosscorrelation score (xCorr) was higher than 2 and the number of matching ions higher than $60 \%$. MS/MS results allowed not only the confirmation of the proteins previously identified by MALDI-TOF, but also the specific isoform of the proteins interacting with MT-3 (see supplemental material, Tables 2 and 3 available online at doi:10.4061/2011/208634). Moreover, the MS/MS allowed for the detection of proteins that were not confidently detected with MALDI-TOF (valosin containing protein, HSP70 glucose-regulated protein and protein 8 , pyruvate kinase 3 , tubulin alpha 3 ) each with at least two peptides and an xCorr value higher than 2 .

Table 1 summarizes the regrouped results of the MALDITOF and MS/MS for all proteins identified and their known function. This information allowed for the classification of the partner proteins into three groups: (1) proteins that are involved in transport, (2) chaperoning/scaffolding and regulation, and (3) glucose metabolism related proteins (metabolic enzymes). A brief description of a representative protein from each group is provided below.

\subsection{Group 1: Exocyst Complex Component 8 (Exo84p).} Exo84p is a component of the exocyst multiprotein complex that plays an important role in targeting and docking the secretory vesicle, containing proteins and lipids, at the plasma membrane [27]. The exocyst multiprotein complex is composed of Sec3p, Sec5p, Sec6p, Sec8p, Sec10p, Sec15p, Exo70p and Exo84p [28]. The exocyst complex plays an essential role in tethering secretory vesicles to 
specific domains of the plasma membrane for exocytosis [29]. Exo84p plays a key role in the organization and the polarized localization of the exocyst complex [29]. Exo84p does interact with Sec5p and/or Sec10p [27], proteins that we were not able to identify with confidence in our data. Exo84p can also interact with Ras and Ral GTPase proteins similar to Rab3a [30]. The Ral-binding domain of Exo84p adopts a plekstrin homology $(\mathrm{PH})$ domain fold, which consists of a seven-stranded $\beta$-sandwich containing two orthogonal antiparallel $\beta$-sheets and an abutting C-terminal $\alpha$-helix [28].

3.2. Group 2: DRP-2/CRMP2. Dihydropyrimidinase-Related Protein 2 (DRP-2) is a protein that is related to dihyropyrimidinase and is usually referred to as collapsing response mediator protein (CRMP2). Five isoforms of CRMPs exists in humans (CRMP1-CRMP5), which are approximately $70 \%$ identical to each other. There is no known enzymatic activity for the DRP-2 protein family, although it is 58\% identical to the human dihydropyrimidinase that catalyzes the second step in pyrimidine degradation. DRP-2 is known to be involved in neuronal differentiation, axonal guidance and neuronal polarity. The protein is highly expressed in the developing nervous system. Overexpression of DRP-2 induces the growth of numerous axons and it is also involved in the maturation of neurites and preexisting dendrites to axons [31]. DRP-2 binds to tubulin heterodimers promoting microtubule assembly [32]. However, this binding is inactivated by the phosphorylation of Thr514 by glycogen synthase kinase $3 \beta$ (GSK-3 $\beta)$ [33].

3.2.1. 14-3-3 Zeta. 14-3-3 proteins were first identified in 1967 during a study of the soluble acidic proteins from mammalian brains [34]. They are small proteins $(\sim 30 \mathrm{kDa})$ that form both homo- and heterodimers. They include seven isoforms in human cells. The importance of these proteins was not recognized until later when it was discovered that these proteins can activate tyrosine, tryptophan hydroxylases and Raf and can inhibit protein kinase C [35]. 14-3-3 proteins bind to specific phosphoserine or phosphothreonine motifs (RSXpSXP and RXXXpSXP) in protein targets [36]. 14-3-3 proteins can alter their target proteins using three ways: (1) conformational change, (2) physical occlusion of sequence-specific or structural protein features, and (3) scaffolding [35]. They can, thereby, prevent the interaction with other proteins, regulate the subcellular distribution of proteins or protect proteins from proteolysis [37].

14-3-3 zeta modulates the action of proteins that are involved in the cell cycle, transcriptional control, signal transduction, intracellular trafficking and regulation of ion channels [38]. Recently, 14-3-3 zeta was proposed to be a "Sweeper" of misfolded proteins [39].

3.3. Group 3: Enolase. Enolase, also called 2-phospho-Dglycerate hydrolase, is a metal-activated enzyme that catalyzes the dehydration of 2-phospho-D-glycerate to phosphoenolpyruvate (pyruvate kinase substrate) [40]. In vertebrates, three tissue-specific isoform are found: nonneuronal
TABle 1: Proteins interacting with MT-3 identified with MALDI$\mathrm{TOF}$ and MS/MS, and their functions.

\begin{tabular}{|c|c|c|c|}
\hline Protein ID & $\begin{array}{c}\text { MALDI- } \\
\text { TOF }\end{array}$ & MS/MS & Function \\
\hline Exo84p & $\mathrm{x}$ & & Transport \\
\hline ATP synthase $\beta$ subunit & $\mathrm{x}$ & $\mathrm{x}$ & Transport \\
\hline $\begin{array}{l}\text { Valosin containing } \\
\text { protein }\end{array}$ & & $\mathrm{x}$ & \\
\hline HSP 84 & $\mathrm{x}$ & $\mathrm{x}$ & Chaperoning \\
\hline $\begin{array}{l}\text { HSP70 glucose-regulated } \\
\text { protein }\end{array}$ & & $\mathrm{x}$ & Chaperoning \\
\hline HSP70 protein 8 & & $\mathrm{x}$ & Chaperoning \\
\hline Tubulin alpha 3 & & $\mathrm{x}$ & Scaffold \\
\hline$\gamma$-Actin & $\mathrm{x}$ & & \\
\hline$\beta$-Actin & $\mathrm{x}$ & $\mathrm{x}$ & Scaffold \\
\hline $14-3-3$ zeta & $\mathrm{x}$ & $\mathrm{x}$ & Scaffold/regulation \\
\hline Pyruvate kinase 3 & & $\mathrm{x}$ & Glycolytic metabolism \\
\hline$\gamma$-Enolase & & $\mathrm{x}$ & Glycolytic metabolism \\
\hline$\alpha$-Enolase & $\mathrm{x}$ & $\mathrm{x}$ & Glycolytic metabolism \\
\hline Creatine Kinase BB & $\mathrm{x}$ & $\mathrm{x}$ & Glycolytic metabolism \\
\hline Aldolase 3 & & $\mathrm{x}$ & \\
\hline Aldolase 1 & $\mathrm{x}$ & $\mathrm{x}$ & Glycolytic metabolism \\
\hline Malate dehydrogenase & $\mathrm{x}$ & $\mathrm{x}$ & Glycolytic metabolism \\
\hline DRP-2 & $\mathrm{x}$ & $\mathrm{x}$ & Neuronal growth \\
\hline DRP-3 & & $\mathrm{x}$ & \\
\hline
\end{tabular}

enolase $(\alpha)$, neuron-specific enolase $(\gamma)$ and muscle-specific enolase $(\beta)$ [41]. Enolase exists in a physiological state as a dimer, with the two monomer subunits oriented in an antiparallel manner [40]. The dimerization process depends on the two $\mathrm{Mg}^{2+}$ that are bound to the monomers and the divalent metal ion plays a critical role in catalysis [40]. Although $\mathrm{Mg}^{2+}$ is the primary activator of enolase, the enzyme also binds zinc strongly, which has a lower activity [40].

Studies in yeast, vertebrates and mammalian cells have shown that $\alpha$-enolase may have other functions such as thermal tolerance, growth control [42, 43], and hypoxia tolerance [44]. Enolase also functions as a cell surface receptor for plasminogen (PGn), which has a neurotrophiclike effect on neurons and enhances the neurite outgrowth of neocortical explants $[42,43,45]$.

The cellular localization of $\alpha$-enolase is known to be predominantly cytosolic [46] and can translocate to the plasma membrane in either the homodimeric $(\alpha \alpha)$ or heterodimeric $(\alpha \gamma)$ form. While the $\gamma$ isoform is mainly detected in cells of neuronal origin, the $\alpha$ isoform is widely distributed among different tissues [47]. The $\alpha \alpha$ isoenzyme (nonneuronal) is expressed in many tissues, while the $\beta \beta$ isoenzyme occurs exclusively in muscle. The $\gamma \gamma$ isoenzyme (neuronal) is present in neurons and neuroendocrine tissues [48].

The $\alpha \gamma$ and $\gamma \gamma$ isoforms are the predominant dimers in the brain, representing the neuron-specific enolases [49]. 
Specifically, the $\gamma$-type enolase subunit is mainly located in neurons while $\alpha$-type subunits are mostly found in glial cells [49].

\section{Discussion}

MT-3 by itself is not toxic nor does it inhibit the growth of neurons. Indeed, it maintains the survival of neurons in culture [50]. MT-3 knockout mice show a higher susceptibility to kainic acid induced neuronal injury, while mice overexpressing MT-3 show enhanced resistance [51]. These results suggest that MT-3 may play a neuroprotective role against toxic substances. MT-3 is abundantly expressed in astrocytes of normal brain $[1,52]$. Moreover, when added to neuronal cell cultures that are exposed to amyloid- $\beta$ peptides, MT-3 enhanced the resistance of the cells against the amyloid- $\beta$ toxicity. This activity is now known as the MT-3 antiamyloid activity [53]. From these activities, one can conclude that MT-3 needs to be secreted into the extracellular milieu. Indeed, although MT-3 does not have any signal sequence, a 23-day-old astrocytes cell culture did secrete MT-3 into the media [50]. A recently published results [24] showed a very important difference in the secretion of MT- 1 and 2 being triggered only in the presence of $\mathrm{Zn}$ and Interleukin-1, neither of these factors have been implicated in MT-3 secretion [50], which we propose is mediated by one or more of the specific partner protein interactions identified in this study.

The subcellular localization of MT-3 in rat brain astrocytes showed an association with organelles involved in the secretion pathway-free ribosomes, rough endoplasmic reticulum, small vesicles, the outer membrane of the mitochondria, plasma membrane, and also around the blood vessels [54]. The localization in neurons was mostly found in the axons, dendrites, the synaptic vesicles, and the postsynaptic densities [54]. It is, therefore, reasonable to hypothesize that MT-3 may well be expressed in the astrocytes. We propose that through its interaction with some of the proteins that we have identified, MT-3 is secreted to the extracellular milieu (blood vessels) and then absorbed by the neurons. Strengthening this argument is the fact that some of the proteins interacting with MT-3 are in fact involved in the transport process: Rab3a, Exo84p. Indeed, Exo84p is a subunit of the exocyst complex, which is important in intracellular trafficking. In metazoa, Exo84p has a $\mathrm{PH}$ domain towards its $\mathrm{N}$-terminus. $\mathrm{PH}$ domains share little sequence conservation, but all have a common fold, which is electrostatically polarized. They are often involved in targeting proteins to the plasma membrane, with a few displaying strong specificity in lipid binding. $\mathrm{PH}$ domains are found in cellular signaling proteins such as serine/threonine kinase, tyrosine kinases, regulators of G-proteins, endocytotic GTPases adaptors, as well as in cytoskeletal associated molecules and in lipid-associated enzymes. Exo84p can also interact with Ras and Ral GTPase proteins similar to Rab3A [30]. Rabphilin3A, a downstream effector of Rab3A that binds the GTP-bound form of Rab3A [55], also binds 14-3-3, another protein found in the MT3 multiprotein complex [56]. 14-3-3 has also been shown to interact with Sec23, a GTPase activating protein and a component of the Sec23p-Sec24p heterodimeric complex of the COPII vesicle coat, which is involved in ER to Golgi transport in S. cerevisiae [57].

Based upon the above, a model for the secretion of MT-3 is proposed. The secretion is regulated through the "mitochondrial pathway" and involves MT-3's interaction with Rab3A, Exo84p and the exocyst complex, 14-3-3 zeta, and rabphilin3A (Figure 3, Left panel). Once MT-3 is secreted, PGn and/or $\alpha \gamma$-enolase could facilitate its uptake by the neurons, which have been shown to uptake MT-1/2 [24]. Indeed, $\alpha \gamma$-enolase is located on the cell surface of a certain population of neurons and has been shown to interact with the microglia-derived PGn, which has a neurotrophiclike effect on neurons [43].

The neuronal MT- 3 could then regulate the growth of the neurons through either or both of the following mechanisms: (i) Considering that MT-3 has a GIF activity, one could speculate that MT-3 might inhibit PGn. This may well be facilitated through the common interacting protein enolase. (ii) DRP-2 is known to regulate neuronal differentiation, axonal guidance and neuronal polarity. Moreover, DRP-2 is involved in the maturation of neurites and preexisting dendrites to axons, and its overexpression induces the outgrowth of numerous axons [31]. On the other hand, MT3 suppresses the neurite extension of neurons in the early period of differentiation and suppresses cell death of more differentiated neurons [50]. Based on this, we hypothesize that through its interaction with DRP-2, MT-3 could regulate the growth of the neurons (Figure 3, right panel).

The above model conforms to the neuroactivity of MT3 and its reported reduction in $\mathrm{AD}$ brain tissue [52], where the above regulatory interactions would be disrupted. The trigger might well be the oxidative stress or other hallmark pathology associated with the disease: the neurofibrillary tangles or the plaques. Most proteins found in the multiprotein complex(es) with MT3 have in fact been shown to be altered in $\mathrm{AD}$ patients. 14-3-3 zeta is overexpressed in the temporal cortex of patient with cognitive impairment, leading to its implication in the AD neuropathology [58]. Glyceraldehyde-3-phosphate dehydrogenase, pyruvate kinase, malate dehydrogenase and 14-3-3 zeta were found to be significantly oxidized both in rat brains and in cell cultures that were exposed to amyloid- $\beta_{42}[59,60] . \gamma$-enolase and malate dehydrogenase were found to be downregulated in the Tg2576 AD mouse model, whereas pyruvate kinase, $\alpha$ enolase, and DRP-2 were upregulated [61]. The expression of DRP-2 in the hippocampal neurons promotes axon elongation. This latter function seems to depend upon the phosphorylation of DRP-2 by GSK-3 $\beta[31,32,62,63]$. 14-3-3 zeta has been proposed to be an effector of tau phosphorylation by GSK-3 $\beta$ and hyperphosphorylated DRP2 has been detected within neurofibrillary tangles from the brains of Alzheimer's disease patients [62, 64]. The hyperphosphorylation of DRP-2 could inhibit the interaction with MT-3 leading to the alteration of the GIF activity of MT3 and, therefore, to the outgrowth of the neurons. It is noteworthy, to reemphasize the positive correlation found between the GIF activity and the neurofibrillary tangles [3]. 


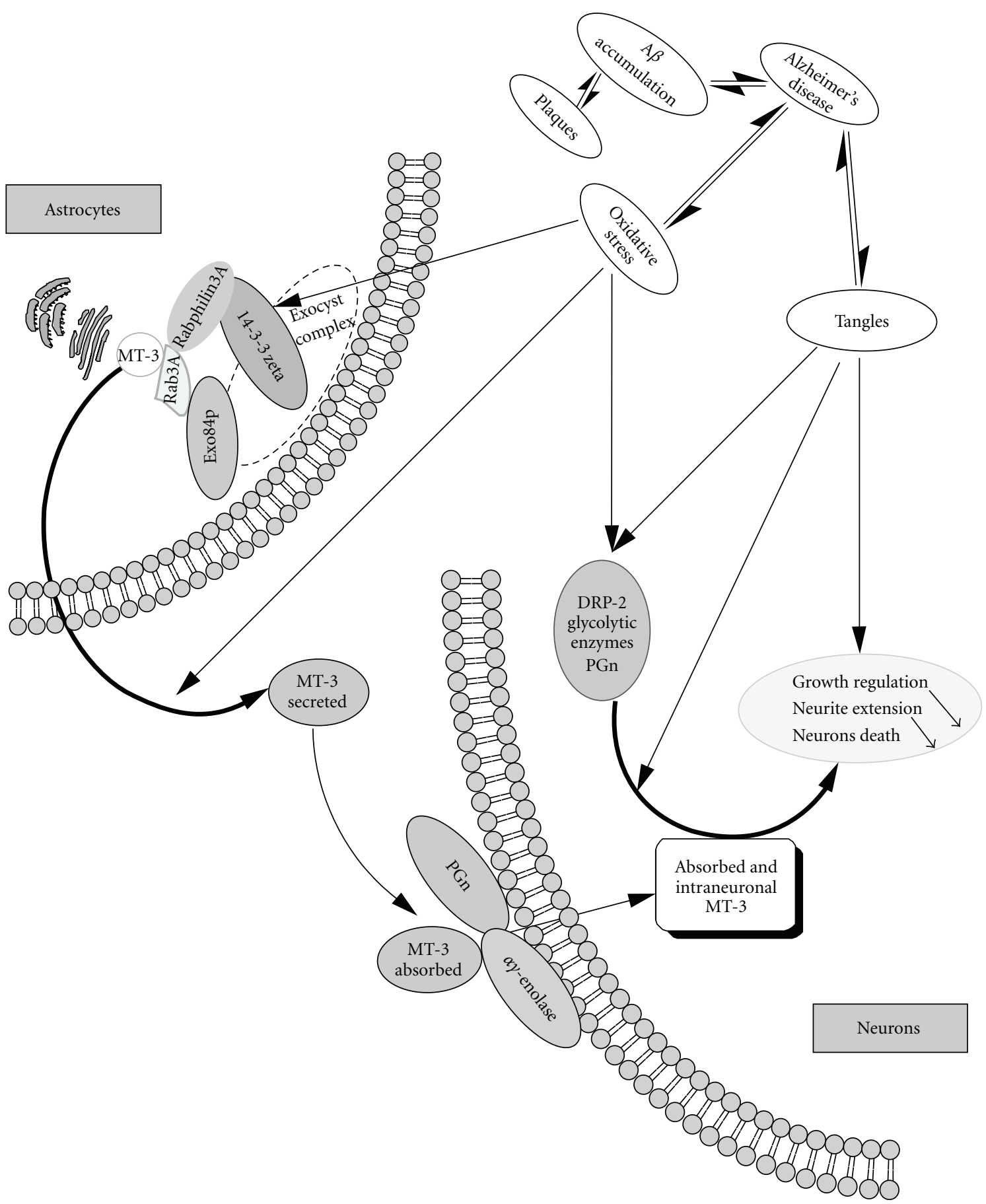

FIgURE 3: Schematic model of the interactions of MT-3 and its implication on the biological functions of MT-3. The hypothetical model describes the process of secretion of MT-3, from the astrocytes into the extracellular milieu, through its interaction with Rab3A, 14-3-3 zeta, Exo84p (Left panel). The uptake of MT-3 into the neurons and their growth regulation: uptake is facilitated through the interaction with the plasminogen (PGn) and enolase (either, $\alpha \gamma$ or $\gamma \gamma$ ). Once inside the neurons, MT-3 protects the neurons from the extension and the outgrowth through its interaction with DRP-2. In Alzheimer's disease, oxidative stress alters several proteins involved in the interaction with MT-3, therefore potentially affecting the pathway of secretion and/or the uptake.

To summarize, novel new partner proteins for MT3 have been identified. The identities of a couple of these associated proteins, 14-3-3 and Exo84p, provide a basis for a biologically relevant model for the processing of MT3. In view of the size of MT3, we favor an interaction model involving multiple interactions as opposed to single complex. The interaction model we envision is a thiol/disulfide interchange model, which could involve one or more of the many cysteines in MT3. Indeed, Rab3A, 14-3-3Z, Exo84p, $\alpha$-enolase, all have cysteines that could participate in this 
thiol/disulfide interchange model. In this regard, it is important to note that published work [65] has established that the beta domain of MT3 binds 4 copper leaving two cysteines free to participate in such a mechanism. This is in contrast to MT1 and 2, both of which bind either 3 zinc or 6 coppers to the beta domain leaving no free cysteines to participate in such a thiol exchange mechanism. The proposed model, along with Rab3A [22, 23], promotes the secretion of MT3 from astrocytes. Now in the extracellular milieu, MT-3 is positioned to function consistent with its reported activities: the regulation of neuronal growth and the antagonism of $\beta$-amyloid. Regulation of the growth of neurons could be mediated through two possible mechanisms: (i) direct inhibition of the PGn at the surface of neurons, or (ii) the uptake of MT3 into neurons facilitated by the interaction with enolase located in the cell surface of the neurons. Once taken up by the neurons, MT-3 could then regulate the growth of neurons through its association with DRP2. Further studies are in progress to validate this newly proposed functional model for MT3's role in regulating neuronal growth.

\section{Abbreviations}

AD: Alzheimer's disease,

MT-3: Metallothionein-3,

GIF: Growth inhibitory factor,

Exo84p: Exocyst complex component 8,

PH: Plekstrin homology,

PGn: Plasminogen,

DRP-2: Dihydropyriminase like protein-2,

CRMP: Collapsin response mediator protein,

GSK-3 $\beta$ : Glycogen synthase kinase $(3 \beta)$.

\section{Acknowledgments}

We are very thankful to the help of Bruce Witthuhn and LeeAnn Higgins at the Proteomics Analysis Core and the Mass Spectrometry Consortium for the Life Sciences of the University of Minnesota. Partial support for this research from Minnesota Medical Foundation (MMF) and BMBB department is gratefully acknowledged.

\section{References}

[1] Y. Uchida, Y. Ihara, and M. Tomonaga, “Alzheimer's disease brain extract stimulates the survival of cerebral cortical neurons from neonatal rats," Biochemical and Biophysical Research Communications, vol. 150, no. 3, pp. 1263-1267, 1988.

[2] Y. Uchida and M. Tomonaga, "Neurotrophic action of Alzheimer's disease brain extract is due to the loss of inhibitory factors for survival and neurite formation of cerebral cortical neurons," Brain Research, vol. 481, no. 1, pp. 190-193, 1989.

[3] Y. Uchida, K. Takio, K. Titani, Y. Ihara, and M. Tomonaga, "The growth inhibitory factor that is deficient in the Alzheimer's disease brain is a 68 amino acid metallothioneinlike protein,” Neuron, vol. 7, no. 2, pp. 337-347, 1991.

[4] J. H. R. Kägi and A. Schäffer, "Biochemistry of metallothionein,” Biochemistry, vol. 27, no. 23, pp. 8509-8515, 1988.
[5] J. D. Otvos, H. R. Engeseth, D. G. Nettesheim, and C. R. Hilt, "Interprotein metal exchange reactions of metallothionein," Experientia. Supplementum, vol. 52, pp. 171-178, 1987.

[6] M. Vašák and D. W. Hasler, "Metallothioneins: new functional and structural insights," Current Opinion in Chemical Biology, vol. 4, no. 2, pp. 177-183, 2000.

[7] S. H. Garrett, V. Phillips, S. Somji et al., "Expression of MT3 protein in the human kidney," Toxicology Letters, vol. 126, pp. 69-80, 1999.

[8] C. J. Quaife, S. D. Findley, J. C. Erickson et al., "Induction of a new metallothionein isoform (MT-IV) occurs during differentiation of stratified squamous epithelia," Biochemistry, vol. 33, no. 23, pp. 7250-7259, 1994.

[9] C. D. Klaassen, Metallothionein IV, Birkhauser, Basel, Switzerland, 1999.

[10] P. K. Datta and E. A. Lianos, "Nitric oxide induces metallothionein-I gene expression in mesangial cells," Translational Research, vol. 148, no. 4, pp. 180-187, 2006.

[11] D. Duval, M. Trouillas, C. Thibault et al., "Apoptosis and differentiation commitment: novel insights revealed by gene profiling studies in mouse embryonic stem cells," Cell Death and Differentiation, vol. 13, no. 4, pp. 564-575, 2006.

[12] K. Zangger, G. Öz, J. D. Otvos, and I. M. Armitage, "Three-dimensional solution structure of mouse [Cd]metallothionein-1 by homonuclear and heteronuclear NMR spectroscopy," Protein Science, vol. 8, no. 12, pp. 2630-2638, 1999.

[13] J. D. Otvos and I. M. Armitage, "Structure of the metal clusters in rabbit liver metallothionein," Proceedings of the National Academy of Sciences of the United States of America, vol. 77, no. 12, pp. 7094-7098, 1980.

[14] K. Zangger and I. M. Armitage, "Metallothioneins," in Handbook of Metalloproteins, A. Messerschmidt, W. Bode, and M. Cygler, Eds., vol. 3, pp. 353-364, John Wiley \& Sons, Chichester, UK, 2004.

[15] R. D. Palmiter, "Constitutive expression of metallothionein-III (MT-III), but not MT-I, inhibits growth when cells become zinc deficient," Toxicology and Applied Pharmacology, vol. 135, no. 1, pp. 139-146, 1995.

[16] Y. Uchida and Y. Ihara, "The N-terminal portion of growth inhibitory factor is sufficient for biological activity," Journal of Biological Chemistry, vol. 270, no. 7, pp. 3365-3369, 1995.

[17] A. K. Sewell, L. T. Jensen, J. C. Erickson, R. D. Palmiter, and D. R. Winge, "Bioactivity of metallothionein-III correlates with its novel b-domain sequence rather than metal binding properties," Biochemistry, vol. 34, pp. 4740-4747, 1995.

[18] Z. C. Ding, X. C. Teng, B. Cai et al., "Mutation at Glu23 eliminates the neuron growth inhibitory activity of human metallothionein-3," Biochemical and Biophysical Research Communications, vol. 349, no. 2, pp. 674-682, 2006.

[19] I. El Ghazi, B. L. Martin, and I. M. Armitage, "Metallothionein-3 is a component of a multiprotein complex in the mouse brain," Experimental Biology and Medicine, vol. 231, no. 9, pp. 1500-1506, 2006.

[20] A. M. Tokheim, I. M. Armitage, and B. L. Martin, "Development of an antiserum specific for isoform 3 of metallothionein," Journal of Biochemical and Biophysical Methods, vol. 63, no. 1, pp. 43-52, 2005.

[21] D. W. Lahti, J. D. Hoekman, A. M. Tokheim, B. L. Martin, and I. M. Armitage, "Identification of mouse brain proteins associated with isoform 3 of metallothionein," Protein Science, vol. 14, no. 5, pp. 1151-1157, 2005. 
[22] Q. H. Kang, Q. L. Chen, H. W. Ren, and B. G. Ru, "Growth inhibitory factor (GIF) directly interacts with G-protein Rab3a," Progress in Biochemistry and Biophysics, vol. 28, no. 6, pp. 883-884, 2001.

[23] M. Knipp, G. Meloni, B. Roschitzki, and M. Vašák, "Znmetallothionein-3 and the synaptic vesicle cycle: interaction of metallothionein-3 with the small GTPase Rab3A," Biochemistry, vol. 44, no. 9, pp. 3159-3165, 2005.

[24] R. S. Chung, M. Penkowa, J. Dittmann et al., "Redefining the role of metallothionein within the injured brain: extracellular metallothioneins play an important role in the astrocyteneuron response to injury," Journal of Biological Chemistry, vol. 283, no. 22, pp. 15349-15358, 2008.

[25] A. M. Tokheim, I. M. Armitage, and B. L. Martin, "Antiserum specific for the intact isoform-3 of metallothionein," Journal of Biochemical and Biophysical Methods, vol. 63, no. 1, pp. 43-52, 2005.

[26] A. Shevchenko, M. Wilm, O. Vorm, and M. Mann, "Mass spectrometric sequencing of proteins from silver-stained polyacrylamide gels," Analytical Chemistry, vol. 68, no. 5, pp. 850858, 1996.

[27] W. Guo, A. Grant, and P. Novick, "Exo84p is an exocyst protein essential for secretion," Journal of Biological Chemistry, vol. 274, no. 33, pp. 23558-23564, 1999.

[28] G. Dong, A. H. Hutagalung, C. Fu, P. Novick, and K. M. Reinisch, "The structures of exocyst subunit Exo70p and the Exo84p C-terminal domains reveal a common motif," Nature Structural and Molecular Biology, vol. 12, no. 12, pp. 10941100, 2005.

[29] X. Zhang, A. Zajac, J. Zhang et al., "The critical role of Exo84p in the organization and polarized localization of the exocyst complex," Journal of Biological Chemistry, vol. 280, no. 21, pp. 20356-20364, 2005.

[30] N. I. Nicely, J. Kosak, V. De Serrano, and C. Mattos, "Crystal structures of Ral-GppNHp and Ral-GDP reveal two binding sites that are also present in Ras and Rap," Structure, vol. 12, no. 11, pp. 2025-2036, 2004.

[31] T. Yoshimura, Y. Kawano, N. Arimura, S. Kawabata, A. Kikuchi, and K. Kaibuchi, "GSK- $3 \beta$ regulates phosphorylation of CRMP-2 and neuronal polarity," Cell, vol. 120, no. 1, pp. 137-149, 2005.

[32] Y. Fukata, T. J. Itoh, T. Kimura et al., "CRMP-2 binds to tubulin heterodimers to promote microtubule assembly," Nature Cell Biology, vol. 4, no. 8, pp. 583-591, 2002.

[33] R. C. Deo, E. F. Schmidt, A. Elhabazi, H. Togashi, S. K. Burley, and S. M. Strittmatter, "Structural bases for CRMP function in plexin-dependent semaphorin3A signaling," EMBO Journal, vol. 23, no. 1, pp. 9-22, 2004.

[34] B. W. Moore and V. J. Perez, "Specific acidic proteins of the nervous system," in Physiological and Biochemical Aspects of Nervous Integration, F. D. Carlson, Ed., pp. 343-359, PrenticeHall, Englewood Cliffs, NJ, USA, 1967.

[35] D. Bridges and G. B. Moorhead, "14-3-3 proteins: a number of functions for a numbered protein," Science's STKE, vol. 2005, no. 296, pp. 1-10, 2005.

[36] A. J. Muslin, J. W. Tanner, P. M. Allen, and A. S. Shaw, "Interaction of 14-3-3 with signaling proteins is mediated by the recognition of phosphoserine," Cell, vol. 84, no. 6, pp. 889897, 1996.

[37] P. Beguin, R. N. Mahalakshmi, K. Nagashima et al., "14-3-3 and calmodulin control subcellular distribution of Kir/Gem and its regulation of cell shape and calcium channel activity," Journal of Cell Science, vol. 118, no. 9, pp. 1923-1934, 2005.
[38] D. Berg, C. Holzmann, and O. Riess, "14-3-3 proteins in the nervous system," Nature Reviews Neuroscience, vol. 4, no. 9, pp. 752-762, 2003.

[39] K. Kaneko and N. S. Hachiya, "The alternative role of 14-3-3 zeta as a sweeper of misfolded proteins in disease conditions," Medical Hypotheses, vol. 67, no. 1, pp. 169-171, 2006.

[40] V. Pancholi, "Multifunctional $\alpha$-enolase: its role in diseases," Cellular and Molecular Life Sciences, vol. 58, no. 7, pp. 902920, 2001.

[41] C. C. Rider and C. B. Taylor, "Enolase isoenzymes in rat tissues. Electrophoretic, chromatographic, immunological and kinetic properties," Biochimica et Biophysica Acta, vol. 365, no. 1, pp. 285-300, 1974.

[42] L. A. Miles, C. M. Dahlberg, J. Plescia, J. Felez, K. Kato, and E. F. Plow, "Role of cell-surface lysines in plasminogen binding to cells: identification of $\alpha$-enolase as a candidate plasminogen receptor," Biochemistry, vol. 30, no. 6, pp. 1682-1691, 1991.

[43] K. Nakajima, M. Hamanoue, N. Takemoto, T. Hattori, K. Kato, and S. Kohsaka, "Plasminogen binds specifically to $\alpha$-enolase on rat neuronal plasma membrane," Journal of Neurochemistry, vol. 63, no. 6, pp. 2048-2057, 1994.

[44] R. M. Aaronson, K. K. Graven, M. Tucci, R. J. McDonald, and H. W. Farber, "Non-neuronal enolase is an endothelial hypoxic stress protein," Journal of Biological Chemistry, vol. 270, no. 46, pp. 27752-27757, 1995.

[45] K. Nagata, K. Nakajima, N. Takemoto, H. Saito, and S. Kohsaka, "Microglia-derived plasminogen enhances neurite outgrowth from explant cultures of rat brain," International Journal of Developmental Neuroscience, vol. 11, no. 2, pp. 227237, 1993.

[46] A. Subramanian and D. M. Miller, "Mapping the functional domains involved in down-regulation of the c-myc protooncogene," Journal of Biological Chemistry, vol. 275, no. 8, pp. 5958-5965, 2000.

[47] A. Giallongo, D. Oliva, L. Cali, G. Barba, G. Barbieri, and S. Feo, "Structure of the human gene for alpha-enolase," European Journal of Biochemistry, vol. 190, no. 3, pp. 567-573, 1990.

[48] G. I. Murray, M. E. Duncan, W. T. Melvin, and J. E. Fothergill, "Immunohistochemistry of neurone specific enolase with $\gamma$ subunit specific anti-peptide monoclonal antibodies," Journal of Clinical Pathology, vol. 46, no. 11, pp. 993-996, 1993.

[49] A. Keller, A. Berod, M. Dussaillant, N. Lamande, F. Gros, and M. Lucas, "Coexpression of alpha and gamma enolase genes in neurons of adult rat brain," Journal of Neuroscience Research, vol. 38, no. 5, pp. 493-504, 1994.

[50] Y. Uchida, F. Gomi, T. Masumizu, and Y. Miura, "Growth inhibitory factor prevents neurite extension and the death of cortical neurons caused by high oxygen exposure through hydroxyl radical scavenging," Journal of Biological Chemistry, vol. 277, no. 35, pp. 32353-32359, 2002.

[51] J. C. Erickson, G. Hollopeter, S. A. Thomas, G. J. Froelick, and R. D. Palmiter, "Disruption of the metallothionein-III gene in mice: analysis of brain zinc, behavior, and neuron vulnerability to metals, aging, and seizures," Journal of Neuroscience, vol. 17, no. 4, pp. 1271-1281, 1997.

[52] W. H. Yu, W. J. Lukiw, C. Bergeron, H. B. Niznik, and P. E. Fraser, "Metallothionein III is reduced in Alzheimer's disease," Brain Research, vol. 894, no. 1, pp. 37-45, 2001.

[53] Y. Irie and W. M. Keung, "Anti-amyloid $\beta$ activity of metallothionein-III is different from its neuronal growth inhibitory activity: structure-activity studies," Brain Research, vol. 960, no. 1-2, pp. 228-234, 2003. 
[54] M. Yamada, S. Hayashi, I. Hozumi, T. Inuzuka, S. Tsuji, and H. Takahashi, "Subcellular localization of growth inhibitory factor in rat brain: light and electron microscopic immunohistochemical studies," Brain Research, vol. 735, no. 2, pp. 257264, 1996.

[55] C. Ostermeier and A. T. Brunger, "Structural basis of Rab effector specificity: crystal structure of the small G protein Rab3A complexed with the effector domain of raBphilin-3A," Cell, vol. 96, no. 3, pp. 363-374, 1999.

[56] L. Sun, M. A. Bittner, and R. W. Holz, "Rim, a component of the presynaptic active zone and modulator of exocytosis, binds 14-3-3 through its $\mathrm{N}$ terminus," Journal of Biological Chemistry, vol. 278, no. 40, pp. 38301-38309, 2003.

[57] M. Pozuelo Rubio, K. M. Geraghty, B. H. C. Wong et al., "143-3-Affinity purification of over 200 human phosphoproteins reveals new links to regulation of cellular metabolism, proliferation and trafficking," Biochemical Journal, vol. 379, no. 2, pp. 395-408, 2004.

[58] C. Soulie, A. Nicole, A. Delacourte, and I. Ceballos-Picot, "Examination of stress-related genes in human temporal versus occipital cortex in the course of neurodegeneration: involvement of 14-3-3 zeta in this dynamic process," Neuroscience Letters, vol. 365, no. 1, pp. 1-5, 2004.

[59] R. Sultana, D. Boyd-Kimball, H. F. Poon et al., "Redox proteomics identification of oxidized proteins in Alzheimer's disease hippocampus and cerebellum: an approach to understand pathological and biochemical alterations in AD," Neurobiology of Aging, vol. 27, no. 11, pp. 1564-1576, 2006.

[60] D. Boyd-Kimball, H. F. Poon, B. C. Lynn et al., "Proteomic identification of proteins specifically oxidized in Caenorhabditis elegans expressing human $A \beta(1-42)$ : implications for Alzheimer's disease," Neurobiology of Aging, vol. 27, no. 9, pp. 1239-1249, 2006.

[61] J. S. Su, S. E. Lee, H. B. Jung et al., "Profiling proteins related to amyloid deposited brain of Tg2576 mice," Proteomics, vol. 4, no. 11, pp. 3359-3368, 2004.

[62] A. R. Cole, A. Knebel, N. A. Morrice et al., "GSK-3 phosphorylation of the Alzheimer epitope within collapsin response mediator proteins regulates axon elongation in primary neurons," Journal of Biological Chemistry, vol. 279, no. 48, pp. 50176-50180, 2004.

[63] N. Inagaki, K. Chihara, N. Arimura et al., "CRMP-2 induces axons in cultured hippocampal neurons," Nature Neuroscience, vol. 4, no. 8, pp. 781-782, 2001.

[64] Y. Gu, N. Hamajima, and Y. Ihara, "Neurofibrillary tangleassociated collapsin response mediator protein-2 (CRMP-2) is highly phosphorylated on Thr-509, Ser-518, and Ser-522," Biochemistry, vol. 39, no. 15, pp. 4267-4275, 2000.

[65] G. Meloni, P. Faller, and M. Vašák, "Redox silencing of copper in metal-linked neurodegenerative disorders: reaction of $\mathrm{Zn}_{7}$ metallothionein-3 with $\mathrm{Cu}_{2}$ ions," Journal of Biological Chemistry, vol. 282, no. 22, pp. 16068-16078, 2007. 


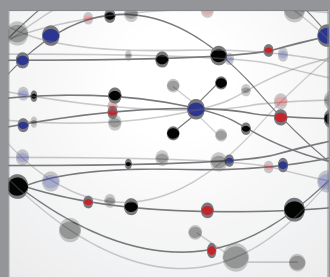

The Scientific World Journal
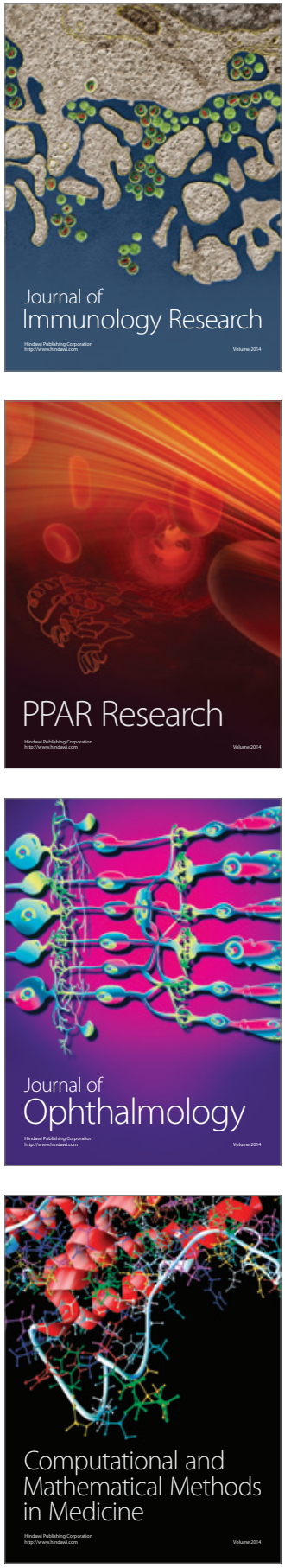

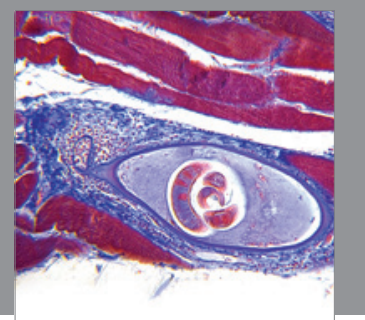

Gastroenterology

Research and Practice
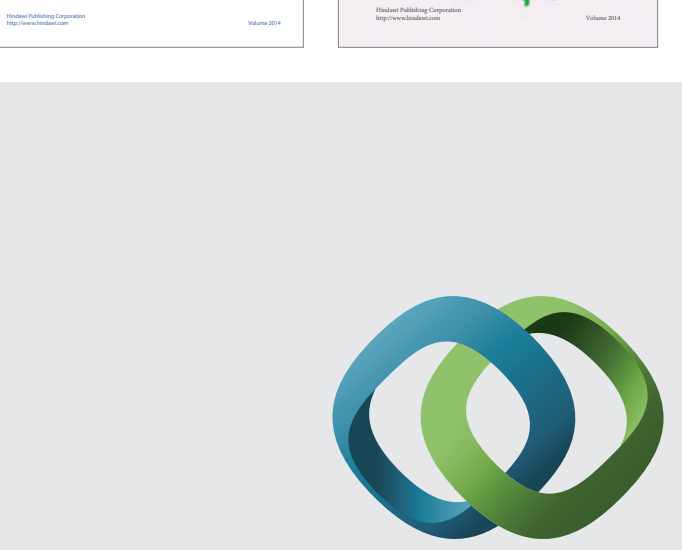

\section{Hindawi}

Submit your manuscripts at

http://www.hindawi.com
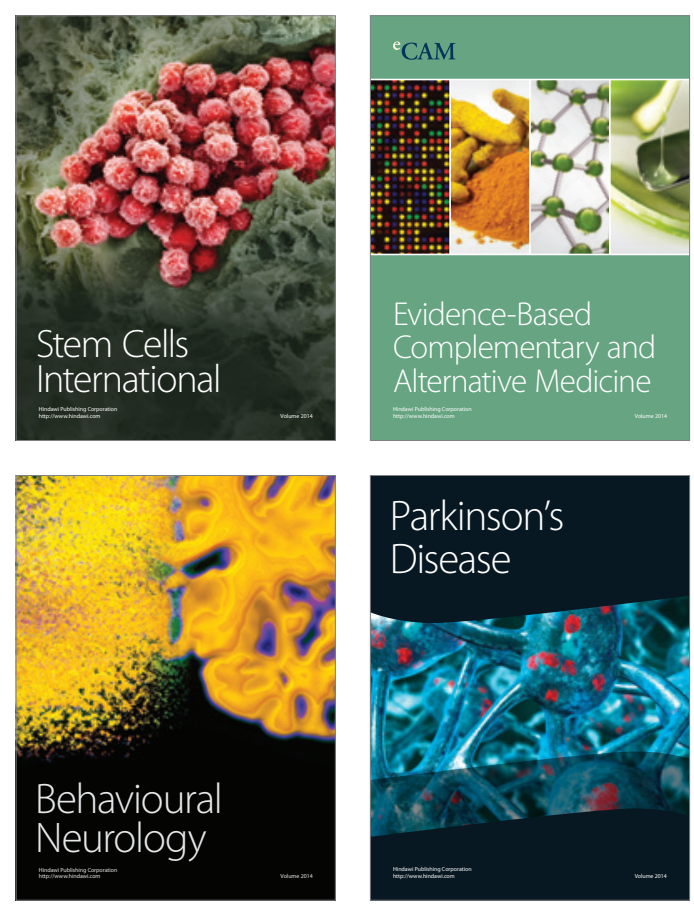

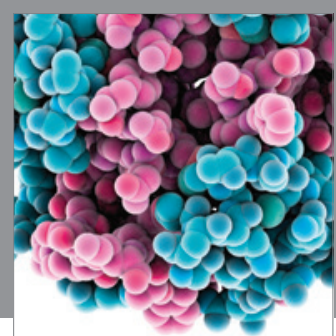

Journal of
Diabetes Research

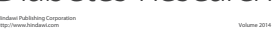

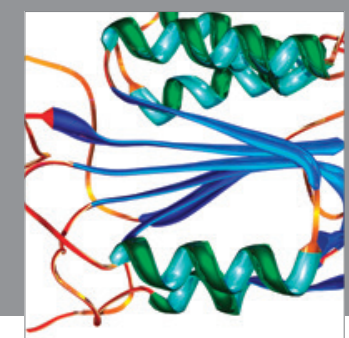

Disease Markers
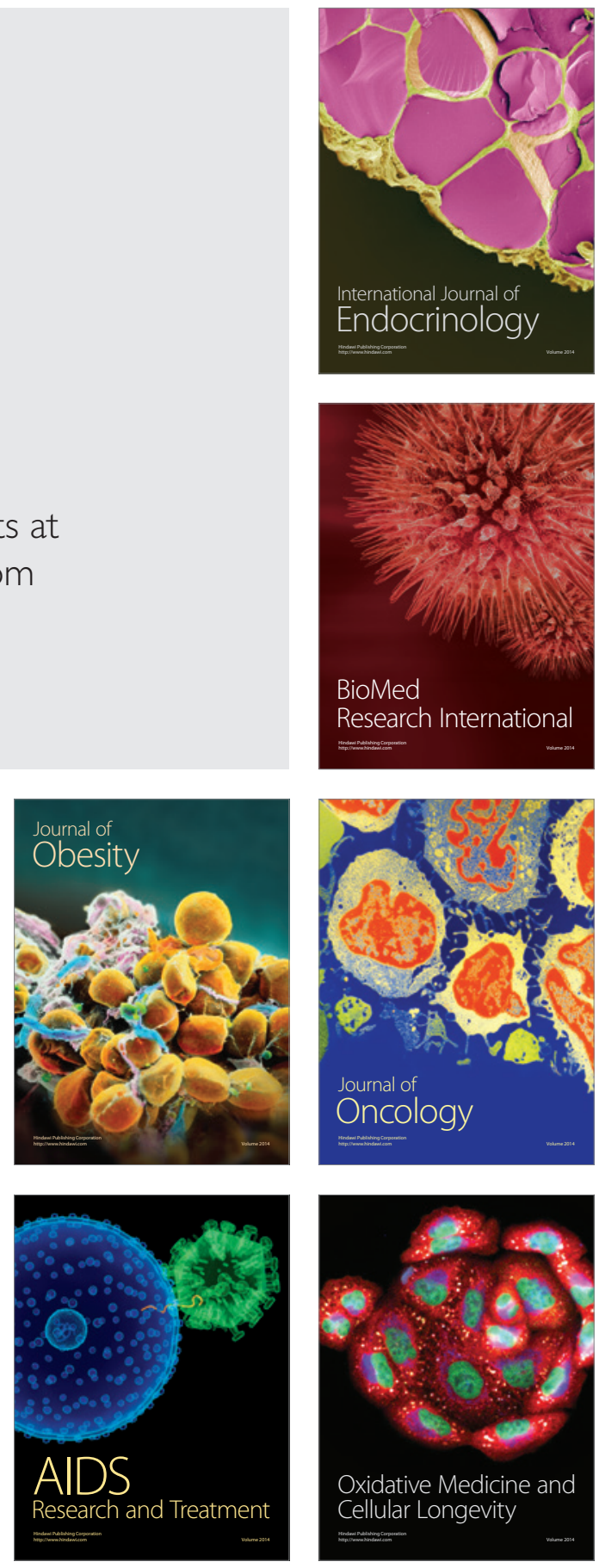